\title{
A interdisciplinaridade e seus reflexos na formação do cirurgião-dentista
}

\author{
Analice Mafi*: Carla Moretto*; Maurício Fernando Nunes Texeira**; Olinda Maria de Fátima \\ Lechmann Saldanha***; Andreas Rucks Varvaki Rados****
}

* Discente de Graduação do Curso de Odontologia, Centro Universitário Univates

** Professor Doutor e Coordenador do Curso de Odontologia do Centro Universitário Univates

*** Professora Doutora do Curso de Psicologia do Centro Universitário Univates

**** Professor do Curso de Odontologia e Coordenador da Clínica Universitária Regional de Educação e Saúde (Cures)

Recebido em 27/06/2016. Aprovado em 21/12/2016.

\section{RESUMO}

O objetivo do trabalho é relatar experiências da inserção de ações interdisciplinares no processo de ensino-aprendizagem do curso de Odontologia da UNIVATES, em Lajeado/RS. Estas atividades foram realizadas na Clínica Universitária Regional de Educação e Saúde nos anos de 2015 e 2016, tais como a Sala de Espera e ações de Apoio Matricial e Institucional. A metodologia adotada com base em relato de experiência e pesquisa bibliográfica baseou-se em princípios da investigação narrativa. A partir do relato é possível concluir que as ações interdisciplinares propiciam experiências diferenciadas em um inovador cenário de ensino e de aprendizagem, o que possivelmente contribuirá para a formação de futuros cirurgiões-dentistas, tendo como referência o cuidado humanizado e a atenção integral à saúde. Esta vivência também possibilitou o fortalecimento da relação entre os profissionais e acadêmicos de diferentes cursos e a conexão com as ações de saúde.

Descritores: Educação em Odontologia. Pesquisa Interdisciplinar. Formação de recursos humanos.

\section{INTRODUÇÃO}

Este artigo foi produzido a partir de reflexões contextuais sobre a vigente concepção de saúde ${ }^{1}$ e assistência à saúde ${ }^{2}$ visando ampliar sua compreensão. A contextualização de espaço e tempo mostra-se uma alternativa que possibilita o entendimento de saúde para as pessoas e, não é de se admirar que desde os primórdios a humanidade empenha-se em enfrentar seu estado de saúde-doença de distintas formas, com diferentes conceitos.

Consequentemente, chega-se ao vigente conceito de saúde, caracterizado por vezes um utópico estado de bem-estar, por outras um direito a vida ${ }^{3}$, ao corpo, à satisfação, ao júbilo, questões estas que perpassam, ou não, a prática 
profissional na área da saúde. Por todos estes caminhos transpassa a noção do que é saúde, de como promovê-la e, por isso, a importância de conhecer seus fundamentos.

Eventualmente, ao examinarem-se as práticas cotidianas relacionadas ao processo saúde-doença, passa despercebida a ideia acima cogitada, de que o que se está fazendo parece não ter um porquê. Justamente neste contexto, este trabalho intenta justificar sua existência, assim como busca justificar a própria realização das práticas experienciadas junto à Clínica Universitária de Educação e Saúde (CURES), em estágios e vivências interdisciplinares, pelas estudantes dos cursos da área da saúde.

A tendência mundial das relações e gestões de saúde, abarcadas pelo Brasil na Constituição Federal de 1988, possibilitou essa inserção de novas faces ao padrão de saúde antes feito no Brasil. A saúde passou a ser um direito de toda a população nacional, inclusive estrangeiros, além de ter acesso aos mais diversos serviços sanitários ${ }^{3}$.

Com o passar dos anos a gestão sanitária, embasada em documentos de referência (Conferência de Alma-Ata e Ottawa, lei 8141/90) e diretrizes, passou a integrar a conceituação da saúde (atual conceito) aos seus serviços, fato que permitiu a abertura para mudanças na forma de promover o cuidado à saúde, pela interdisciplinaridade e pela prevenção, conforme as tendências de estudos e relatórios mundiais. A partir disso, chegou-se a uma definição mais adequada do que a saúde representa no Brasil, contudo este será o último ponto a ser desenvolvido por este trabalho

Deste modo, inicialmente abordar-se-á um relatório das experiências junto ao espaço interdisciplinar da CURES, descrevendo não apenas a proposta do serviço-escola, mas, também as atividades realizadas no mesmo.

Em prosseguimento, serão apresentadas as teorias que fundamentam todo o processo saúde-doença, que estão vinculados ao tema inicial e ao mesmo tempo, sustentam as práticas das acadêmicas de Odontologia. Ainda, descrever o possível aproveitamento e a influência desta experiência na formação do futuro cirurgião-dentista.

Utilizou-se princípios da investigação narrativa a partir de relatórios com as práticas mais significativas ao longo do semestre letivo vivenciado por duas estudantes. O serviço-escola realiza ações interdisciplinares relativas à humanização, promoção de saúde e prevenção de doenças com nove diferentes cursos. As atividades realizadas sempre eram precedidas de estudo sobre as teorias utilizadas. As narrativas das estudantes em questão também foram acompanhadas de uma revisão bibliográfica consistente e condizente de uma maturidade acadêmica incomum para estudantes de primeiro semestre.

A possibilidade de vivenciarem situações diversas à uma formação tradicional contribuiu com o horizonte de atuação enquanto profissionais da Odontologia, conforme o próprio relato das estudantes. Esses eventos significativos foram capazes de mobilizá-las para o estudo de artigos científicos e discussões com outros estudantes e profissionais. Apesar das dificuldades inerentes para estudantes de primeiro semestre, ambas foram capazes de superar tais barreiras, com base em suas experiências prévias e construção de autonomia demonstradas no processo de elaboração e redação dos relatórios que serviram de ponto de partida para o presente manuscrito.

Um melhor embasamento teórico se fez necessário, com vistas à publicação em periódico científico. Os demais autores contribuíram com seus vieses de entendimento sobre os temas apresentados pelas estudantes, sempre as estimulando na redação das ideias e teorias discutidas. A narrativa, portanto, iniciou-se com uma atividade acadêmica e culmina com uma 
publicação científica.

\section{FUNDAMENTOS DO PROCESSO SAÚDE-DOENÇA E DETERMINANTES SOCIAIS DE SAÚDE}

Estudos relatam a dificuldade da definição conceitual do que é saúde desde a Grécia Antiga, contudo avanços aconteceram até chegar-se a um conceito ampliado ${ }^{4}$. Deste modo, a Organização Mundial da Saúde conceitua a saúde como "um estado de completo bem-estar físico, mental e social e não meramente a ausência de doença ou enfermidade"1. Além de, no Brasil, a legislação vigente reconhecê-la como "direito de todos e dever do Estado, garantido mediante políticas sociais e econômicas que visem à redução do risco de doença e outros agravos e ao acesso universal e igualitário às ações e serviços para sua promoção, proteção e recuperação"3.

$\mathrm{Na}$ mesma linha de estudos existem documentos que relatam saúde como "um bem e um direito social, em que cada um e todos possam ter assegurados o exercício e a prática do direito à saúde, a partir da aplicação e utilização de toda a riqueza disponível, conhecimentos e tecnologia desenvolvidos pela sociedade nesse campo, adequados às suas necessidades, abrangendo promoção e proteção da saúde, prevenção, diagnóstico, tratamento e reabilitação de doenças",.

No entanto, não há uma barreira que delimita os conceitos de saúde e doença, como afirma Vianna $(2016)^{6}$ :

"Não existe um limite preciso entre a saúde e a doença, mas uma relação de reciprocidade entre ambas; entre a normalidade e a patologia, na qual os mesmos fatores que permitem ao homem viver (alimento, água, ar, clima, habitação, trabalho, tecnologia, relações familiares e sociais) podem causar doenças. Essa relação é demarcada pela forma de vida dos seres humanos, pelos determinantes biológicos, psicológicos e sociais".

Ou seja, o processo saúde-doença, em síntese, "representa o conjunto de relações e variáveis que produzem e condicionam o estado de saúde e doença de uma população", a partir dos determinantes já citados e que serão esmiuçados posteriormente neste texto. Em última instância, o processo saúde-doença se matiza de acordo com "o conceito do que é ser ou estar doente ou o que é ser ou estar saudável"7.

$\mathrm{O}$ autor ainda complementa:

"Surgiram vários modelos expressando a explicação e compreensão da saúde, da doença e do processo saúde/doença, como o modelo epidemiológico baseado nos três componentes - agente, hospedeiro e meio, considerados como fatores causais -, evoluindo para modelos mais abrangentes, como o do campo de saúde, envolvendo ambiente (não apenas o ambiente físico), estilo de vida, biologia humana e sistema/serviços de saúde, numa permanente inter-relação e interdependência" .

Isso vem em concordância com as atividades realizadas pelas estudantes, nas quais se pode averiguar e delimitar as teorias e conceitos de saúde além de ser possível sentir este processo junto aos usuários, e correlação entre o estado de saúde ou doença destes. Ademais, averiguou-se que tanto o processo de doença, quanto o transpasse para um nível (ou sentimento) de saúde, sofrem influência dos Determinantes Sociais da Saúde (DSS).

Podendo-se conceituar como DSS todos os fatores sociais, econômicos, culturais, étnicos/ raciais, psicológicos e comportamentais que influenciam a ocorrência de problemas de saúde e seus fatores de risco na população ${ }^{8}$, evidenciase sua ligação com o significado de saúde, ou seja, associado ao bem-estar físico, mental, social e não unicamente relacionado a ausência de enfermidades. Também consiste nas teses que 
envolvem elementos sociais, econômicos, culturais, étnicos, psicológicos e comportamentais, que influem nos impasses ocorrentes na área das ciências biológicas, bem como fatores de ameaça a população 9 .

Então, apesar da diversidade de definições para o termo DSS, leva-se em conta para sua adjetivação, as condições de vida e trabalho dos indivíduos e de grupos da sociedade relacionados juntamente com o estado de saúde. Tais situações eram perceptíveis no espaço da clínica uma vez que havia nela, evidente heterogeneidade cultural. Tal expressão quanto a DSS, tem uma acepção dupla, uma de modo estrutural, através da estratificação social - por exemplo, renda e educação -, e outra intermediária, que são as determinantes causadas pela produção de desigualdades na exposição às situações de saúde, nas condições de vida e no sistema de saúde $^{10}$.

Logo as condições que as pessoas vivem ou trabalham, se inter-relacionam, acima descritas são chamadas de DSS e influenciam nas práticas da vivência por serem fatores-chave de reflexão do poder, posição social (hierarquia), inclusão e ingresso aos serviços. Interferem, portanto, diretamente em como realizar as atividades nas vivências, nos procedimentos, pois, quanto mais adequados estes forem aos determinantes sociais do usuário, melhores tendem a ser os resultados auferidos no tratamento.

Não diferente, este reflexo também será sentido, conforme levantado na hipótese, na formação do profissional cirurgião-dentista, se compreende que os determinantes sociais, aplicados nas vivências refletem de toda maneira no cotidiano da saúde, singularmente em cada indivíduo.

\section{CONTEXTUALIZAÇÃO DO LOCAL DA VIVÊNCIA}

O serviço-escola onde ocorreram as práticas aqui relatadas tem dentre seus objetivos a promoção e educação em saúde. Neste espaço há a integração entre docentes e estudantes da maioria dos cursos da saúde, como Educação Física, Enfermagem, Farmácia, Fisioterapia, Medicina, Nutrição, Odontologia, Pedagogia e Psicologia.

Inaugurado em 2011, o espaço físico da CURES contribui para criar um ambiente agradável e acolhedor para docentes, discentes e usuários. A infraestrutura é composta por recepção centralizada e informatizada, várias salas que podem ser utilizadas para atendimentos individuais ou coletivos, ações didáticas, sala de observação (mini auditório), sala de espelhos, sala dos estagiários (reuniões de equipe), sala dos supervisores (docentes), salas para atividades lúdicas e de integração entre as pessoas em atendimento, seus familiares/acompanhantes e os estagiários da CURES, de lazer e entretenimento, sala de espera (Espaço Conviver), além da sala de estar com cozinha/refeitório e sanitários. Ao sair deste ambiente encontram-se várias árvores, flores, gramíneas e bancos, que por vezes também são utilizados para atendimento. Este ambiente arejado, limpo e claro, de interações, vínculos e cuidado, é construído diariamente por todos os atores que ali circulam.

O serviço-escola possui convênio com três municípios do interior do Rio Grande do Sul: Arroio do Meio, Estrela e Lajeado. Os atendimentos às pessoas referenciadas integram a rede de atenção do Sistema Único de Saúde (SUS), sem custos aos usuários. A contrapartida solicitada aos municípios é a responsabilidade pelo transporte dos usuários até a clínica-escola e a corresponsabilização das equipes locais pelo cuidado aos usuários referenciados. As atividades da CURES são articuladas de forma a integrar o cuidado em saúde com a rede de Saúde, da Educação e de Assistência Social dos municípios. Ou seja, o serviço promove experiências condizentes com o princípio da integralidade e da intersetorialidade por meio da 
articulação entre os pontos da rede do sistema de saúde no atendimento aos usuários. Neste sentido, considera-se que esse princípio é “[...] entendido como conjunto articulado e contínuo das ações e serviços preventivos e curativos, individuais e coletivos, exigidos para cada caso em todos os níveis de complexidade do sistema" ${ }^{2}$.

A incidência do princípio retro qualificado é sentida na prática ao perceber que a rede municipal conveniada encaminha usuários para a avaliação e intervenções da equipe da Clínica Universitária, quando avalia que não tem condições para atender às demandas e necessidades identificadas. Assim, a partir da referência, uma das equipes da CURES realiza o acolhimento da equipe que fez a referência e posteriormente, do usuário referenciado visando a proposição de ações que respondam às necessidades dele, a partir do referencial da interdisciplinaridade, da integralidade e da intersetorialidade. As ações de cuidado são propostas em conjunto com a equipe do município e com o usuário em atendimento, visando o cuidado integral da saúde e a promoção da autonomia da pessoa. Considera-se a autonomia como potencialidade de cada sujeito para escolher entre diferentes alternativas que reconhece ou lhes são ofertadas e decidir o que fazer, no sentido de autogovernar sua vida ${ }^{11}$.

Através do conceito de promoção de saúde como um processo de capacitação das pessoas para aumentar seu controle sobre e melhorar a sua saúde, a atuação da equipe se dá no sentido da ampliação do controle ou domínio dos indivíduos e comunidades sobre os determinantes de sua saúde ${ }^{12}$. Estas articulações oportunizam aos estudantes vivenciar a coordenação do cuidado e fortalecer a comunicação entre os pontos da rede e o usuário dos serviços de saúde, como base para a implementação do princípio da integralidade buscando tornar o usuário, o protagonista de seu cuidado.

Considerando as linhas de cuidado como "imagens pensadas para expressar os fluxos assistenciais seguros e garantidos ao usuário, no sentido de atender às suas necessidades de saúde" "13. Existem no serviço-escola fluxos voltados para a Saúde Mental, Saúde do Trabalhador, Saúde do Idoso, Infanto-Juvenil, usuários com Necessidades Especiais e os respectivos cuidadores.

A partir disto, busca-se trabalhar na lógica da educação permanente, rompendo com o paradigma tradicional, no qual o modelo hegemônico é o médico-centrado e passa a ser usuário-centrado, de tal modo que o sujeito passa a ser o centro das atenções com um tratamento administrado pela humanização na troca de saberes entre os diversos profissionais na área da saúde ${ }^{14}$. Essa ação de saúde busca criar produtos para cuidar, melhorar a qualidade de vida dos usuários, ampliar a percepção e a adaptação quanto ao processo saúde-doença ${ }^{15}$.

Neste caso, a interdisciplinaridade atua como integradora e mediadora da circulação dos discursos disciplinares e como coordenadora do núcleo disciplinar. Há reciprocidade, enriquecimento mútuo e tendência à horizontalização das relações de poder entre os campos ${ }^{16}$.

Como se verifica no contexto até agora discutido, é evidente e relevante a importância da interdisciplinaridade para a proposta atual do fazer saúde, não entendida a interdisciplinaridade apenas como diálogo interprofissional, senão também a escuta da família, a análise do contexto e das condições e experiências, do usuário do sistema.

Conhecidas estas premissas quanto à delimitação das práticas realizadas, segue o artigo para a conceituação das mesmas, da explicação teórica, intentando demonstrar como se caracterizam interdisciplinares, especialmente no que tange aos apoios matricial e institucional e da sala de espera. 


\section{A INFLUÊNCIA NA FORMAÇÃO DO PROFISSIONAL CIRURGIÃO-DENTISTA}

É perceptível que a experiência na CURES influencia na formação do cirurgião-dentista, assim como nos estudantes das demais áreas da saúde. Contudo, a tarefa é árdua quando se trata de trabalhar com interdisciplinaridade, quando no decorrer de séculos, se trabalhou somente com a educação para formação de profissionais tecnicistas.

Como afirma Frigotto $(2008)^{17}$ : “a necessidade da interdisciplinaridade na produção do conhecimento funda-se no caráter dialético da realidade social [..] que nos impõe distinguir os limites reais dos sujeitos[..]. Ou seja, se o processo de conhecimento nos impõe a delimitação de determinado problema isto não significa que tenhamos que abandonar as múltiplas determinações que o constituem.

É importante, então, distinguir estas formações para que os resultados sejam maximizados, possibilitando que o estudante tenha sua formação e prática marcadas pela presença da humanização no processo de ensino e de aprendizagem. Neste sentido, problematizam Ceccim e Feuerwerker (2004) ${ }^{18}$ :

"a formação não pode tomar como referência apenas a busca eficiente de evidências ao diagnóstico, cuidado, tratamento, prognóstico, etiologia e profilaxia das doenças e agravos. Deve buscar desenvolver condições de atendimento às necessidades de saúde das pessoas e das populações, da gestão setorial e do controle social em saúde, redimensionando o desenvolvimento da autonomia das pessoas até a condição de influência na formulação de políticas do cuidado".

Ademais, a interdisciplinaridade pode ser considerada um "alargador" de conhecimentos, que articula a prática e teoria, desenvolve o senso crítico-racional, de forma autônoma, potencializando as possibilidades e capacidades individuais ou coletivas, assim superando a fragmentação do ensino, num viés muito mais humanizado do que simplesmente técnico.

A partir do relato de experiência é possível dizer que as ações interdisciplinares propiciam experiências diferenciadas em um inovador cenário de ensino e de aprendizagem. Contexto que contribuirá para a formação dos futuros cirurgiões-dentistas preparados a proceder atividades em formação humanizada e interligada com outras políticas públicas e diferentes áreas de conhecimento. Esta vivência também possibilitou o fortalecimento da relação entre os profissionais e acadêmicos de diferentes cursos, com a qual aprende-se a ligar fatos e conteúdos, e a conexão com as ações de saúde. Zabala $(1998)^{19}$ considera que "todo conteúdo por mais específico que seja sempre está associado e portanto, será aprendido junto com conteúdo de outra natureza".

Mas para isso, não se dispensa a própria intenção do profissional que está sendo formado:

"Cabe aos profissionais da saúde rever sua prática, buscando entender que não basta trabalhar com as doenças, é necessário compreender o indivíduo no todo como alguém que vive a experiência da necessidade, do adoecimento, carregada de valores e significados subjetivos, únicos, capazes de interferir na qualidade do cuidado prestado. Assim, resta-nos, como profissionais da saúde, enfrentar o desafio de construir estratégias para conceber a saúde no âmbito da atenção básica de forma mais solidária e menos punitiva na convivência com os estilos de vida individuais"

Sem a busca neste sentido, pelo próprio estudante, enquanto em formação, os resultados não serão obtidos. Nada vem ao acaso. Neste aspecto, é possível sentir a influência das vivências na formação do cirurgião-dentista, contudo, sempre se condiciona dito aprendizado às próprias condutas dos educandos. 


\section{RELATANDO PARTE DAS AÇÕES DE SAÚDE VIVENCIADAS}

Na clínica-escola os estudantes de nove cursos diferentes realizam práticas relacionadas à humanização como o acolhimento, que favorece a escuta e a formação de vínculos entre os usuários e a equipe, a identificação de demandas e necessidades dos usuários e seus familiares. As interações e intervenções na sala de espera e as ações de apoio matricial e institucional às equipes de referência também são práticas desenvolvidas pelos estudantes do serviço.

Verissimo e Valle $(2006)^{21}$ destacam o quão significativo o espaço da sala de espera é para ocupar o tempo disponível até o atendimento, em momentos de trabalho, desenvolvendo-se atividades educativas e trocas de experiências. Então, para fazer eficaz a citação teórica, no local - sala de espera -, os usuários utilizam o tempo para ampliar a informação e crescimento mútuo (individual ou coletivo).

As atividades desenvolvidas pelas estudantes aqui descritas, afirmam a importância dada pelos autores anteriormente citados, podendo-se listar algumas destas atividades vivenciadas, tais como Projeto sobre Saúde Bucal, que consistiu na confecção de material educativo com o intuito de esclarecer conceitos de saúde bucal, além de patologias presentes na cavidade oral e sua relação com outras áreas da saúde. As atividades foram apresentadas e discutidas com a equipe de trabalho e os usuários do serviço.

Rodrigues e colaboradores (2009) $)^{22}$ ressaltam que o objetivo da sala de espera é assegurar cuidado humanizado, além de fortalecer o vínculo entre usuário-serviço. Neste âmbito os profissionais podem desenvolver atividades além do cuidado, como orientação à prevenção de doenças transmissíveis ou não, ações de promoção de saúde e orientações sobre temas de interesse das pessoas. Assim, acolhe-se melhor o usuário/família, consequentemente melhora-se a relação entre estes e os profissionais, além de contribuir na humanização do serviço. Sob esta perspectiva e considerando o longo período de permanência dos usuários no serviço-escola, a sala de espera passou a ser denominada de "espaço conviver", compartilhado por usuários e estudantes.

Outro ponto de relevância a ser citado que também foi vivenciado pelas autoras foram momentos musicais, realizados principalmente por usuários, utilizando diversos instrumentos, transpassando todo o sentimento de amor, alegria, tristeza e aflição, motivando os próprios usuários a se permitirem leveza, autoestima e confiança nos atendimentos.

Neste sentido, a participação dos usuários, com suas demandas e necessidades oportunizaram o estudo e o debate sobre vários temas durante os períodos de 2015 e 2016, no Espaço Conviver, voltados para a prevenção, promoção e recuperação da saúde.

As intervenções e assuntos abordados, não se resumiram a isso, destacando-se, ademais: artesanato local, estilos musicais, alimentação saudável, exercícios físicos, saúde bucal, automedicação, diversidade cultural e religiosa, qualidade de vida, planos de saúde privados e o acesso às políticas públicas, obesidade, o cuidado de pessoas com limitações e necessidades especiais, autonomia e outros relacionados.

Para as atividades do Espaço Conviver, utiliza-se linguagem simples, materiais didáticos como cartazes, fôlderes e frases motivadoras de discussão, instrumentos musicais, jogos, citações bibliográficas, CD's e mídias diversas. Pela motivação e interesse dos participantes notou-se a importância que usuários e estudantes demonstraram na troca de conhecimentos e curiosidades esclarecidas com o transcorrer das atividades neste espaço de convivência.

Estudantes e supervisores que acompanham este espaço são orientados a evoluírem as suas impressões em prontuário que 
poderão ser agregados aos prontuários dos usuários, caso tenha ocorrido algum fato significativo. Muitas vezes as falas "isso me lembra a minha adolescência" ou " o momento que eu era independente" no espaço conviver trazem elementos que auxiliam as equipes nas construções dos projetos terapêuticos dos usuários. Neste sentido, nos apoiamos em Merhy (1998) para reconhecer que o trabalho em saúde se realiza sempre mediante o encontro entre trabalhador e usuário, é centrado no trabalho vivo, em ato, visando à produção do cuidado. Segundo o mesmo autor, entre as suas "caixas de ferramentas" o profissional de saúde utiliza aquela que oportuniza mediante a escuta, a construção de vínculos, de confiança, captar a singularidade, o contexto, os modos de viver do usuário, enriquecendo e ampliando o entendimento do profissional de saúde ${ }^{23}$.

As equipes do serviço escola, constituídas por docentes e estudantes também desenvolvem ações de Apoio Matricial e Institucional. Ambos estão interligados, ou seja, relacionados um com o outro, com fins de melhor direcionar as práticas de saúde a serem construídas conjuntamente com a equipe de referência e o apoiador. As ações de apoio são desenvolvidas mediante a demanda encaminhada pela equipe municipal e trata-se de "diretriz e dispositivo para ampliar a capacidade de reflexão, entendimento e análise de coletivos, que assim poderiam qualificar sua própria intervenção, sua capacidade de produzir mais e melhor saúde com os outros" 24 , revelando aqui sua face, talvez, mais importante.

Entretanto, há certas diferenças objetivas entre os apoios mencionados acima. No apoio matricial, o objetivo primordial é assegurar assistência especializada dentro da rede, que pode ser direcionada tanto para o coletivo como ao individual. São ações que visam promover ações integradas que façam sentido para o usuário e para tal se constitua uma rede de cuidados.
Neste sentido, o Apoio Matricial, "reordena a lógica relacional entre profissionais generalistas e especialistas, democratizando as relações de poder das equipes de saúde responsáveis pela clínica e pelo cuidado" ${ }^{25}$, de certo modo, organizando a hierarquia do atendimento, mas sem prever que o superior é mais importante ou mais necessário.

O objetivo do apoio matricial, segundo alguns autores ${ }^{26,28}$, é garantir retaguarda especializada a equipes e profissionais de saúde, integrando suporte assistencial e técnicopedagógico às equipes de referência. Em similar compreensão afirma-se que "o apoio matricial busca personalizar os sistemas de referência e contrarreferência, além de estimular e facilitar o contato direto entre referência encarregada do caso e especialista de apoio". Do mesmo modo, “o apoio matricial é um arranjo na organização dos serviços que complementa as equipes de referência como uma forma de organizar e ampliar a oferta de ações em saúde" 27, 28.

No apoio institucional, resumidamente, o objetivo principal é ampliar a função gerencial, ou seja, busca qualificar a equipe de referência no monitoramento, na avaliação e no planejamento para superar o modo tradicional de fazer gestão. Tenta-se evitar meros procedimentos de físcalização e autoritarismo, além do mais, um dos objetivos do apoio é uma construção entre equipe de referência e apoiador. Possibilita-se, assim, novos modelos de (re)pensar ou agir nos processos de trabalho, para que hajam resultados positivos na cogestão da instituição considerando o apoio institucional como um método e uma estratégia de gestão" ${ }^{26}$.

Aprofunda a contextualização do conceito de apoio institucional a Política Nacional de Humanização (PNH), de 2008:

“[...] é uma função gerencial que reformula o modo tradicional de se fazer coordenação, planejamento, supervisão e avaliação em saúde. Um de seus principais objetivos é 
fomentar e acompanhar processos de mudança nas organizações, misturando e articulando conceitos e tecnologias advindas da análise institucional e da gestão. [...] A diretriz do apoio institucional é a democracia institucional e a autonomia dos sujeitos. Assim sendo, o apoiador deve estar sempre inserido em movimentos coletivos, ajudando na análise da instituição, buscando novos modos de operar e produzir das organizações $[\ldots]^{\prime 27}$.

As equipes da clínica escola têm desenvolvido ações tanto de Apoio Matricial e Institucional, cuja vivência pode ser exemplificada, pelas autoras acadêmicas do curso de Odontologia à um Centro de Referência de Assistência Social (CRAS) em município conveniado com a clínica. Primeiramente, o grupo apoiador formado pelos estudantes dos cursos de fisioterapia, nutrição, odontologia, psicologia e, um professor supervisor, acolheram a demanda do serviço através de reuniões. Em seguida, aprofundam-se por meio de leituras e discussões de referências conceituais sobre as formas de apoio, relatos de casos, protocolos de aplicação, e seus afins.

Depois do preparo teórico, passa-se a observar as atividades do CRAS, e, posteriormente, após vínculo entre profissionais (clínica - serviço referência) e usuários, passa-se a auxiliar na elaboração de propostas de intervenção, com base nas demandas apresentadas pela equipe de referência.

No entanto, o que rege os encontros são as situações e as necessidades apresentadas pela equipe apoiada. Ao final de cada encontro os participantes avaliam e propõem mudanças, se necessário. Da mesma forma, a equipe de apoiadores avalia o processo, problematiza os resultados e planeja as atividades para a continuidade dos encontros, ressaltando que o "trabalho interdisciplinar é voltado à Saúde Coletiva, e preferencialmente deve estar ligado à atividade acadêmica de Prática Supervisionada" $^{29}$.

Para a articulação entre teoria e prática as equipes buscam metodologias para trabalhar com todos os integrantes de forma individual ou coletiva, sempre levando em conta os Determinantes Sociais em Saúde (cultura, educação, etnia, faixa etária, entre outros), a fim de reforçar o vínculo entre usuário e serviço, com vistas a proteger e socializar à família e ao coletivo.

A equipe apoiadora procura respeitar as características particulares de cada usuário e, busca estimular a autonomia dos sujeitos, dividindo-os em grupos de acordo com a faixa etária e peculiaridades. Este serviço trabalha com crianças, adolescentes, jovens, portadores de deficiência, acamados e idosos. Nesses encontros há troca de experiências, onde podem aprender com os relatos dos outros participantes.

Cada usuário era estimulado a desenvolver seu papel na realização da promoção de saúde, através do Projeto Terapêutico Singular. Buscava-se incentivar e conscientizar a importância da participação e engajamento do usuário nesse processo. Além disso, para o desenvolvimento de sua autonomia, trabalhou-se as formas de cuidados a serem tomados em casa, desde a alimentação, higiene bucal, precaução à acidentes domésticos, tudo no sentido da prevenção de agravos e adoecimento. Entre as estratégias adotadas foram realizadas visitas domiciliares tanto de acamados, quanto de idosos independentes, além de rodas de conversa com mães e idosos.

Considerando este contexto e demandas, a equipe de apoiadores procurava contribuir no planejamento e confecção de materiais para a realização das atividades de promoção e educação em saúde, construídos pela equipe de referência e equipe apoiadora, promovendo mais conhecimento e autonomia aos usuários.

Neste sentido, considera-se que o apoio ao 
CRAS vai ao encontro do texto do Guia de Orientação Técnica, elaborado pelo Ministério do Desenvolvimento Social e Combate à Fome Secretaria Nacional de Assistência Social $(2005)^{30}$ no que tange ao seu objetivo:

"Oferecer espaços de convívio, com a garantia de acessibilidade, e o objetivo de promoção de autoconhecimento quanto à condição de vida, a relação familiar e de vizinhança, favorecendo um processo de envelhecimento ativo e saudável, a motivação para novos projetos de vida e a prevenção ao isolamento e ao asilamento; Suas atividades devem incluir o conhecimento, promoção e defesa de direitos, conhecimento de experiências de vida, desenvolvimento de projetos intergeracionais que valorizem conhecimentos e experiências e potencialidades para o exercício do protagonismo Social.

O apoio matricial contribui significativamente para potencializar o trabalho das equipes destas instituições, que por vezes trabalham com escassos recursos, dificuldades de espaço e falta de projetos para desenvolvimento dos serviços de forma adequada.

É neste contexto que as atividades realizadas pelas equipes da CURES, tanto na sala de espera e nos apoios à rede de saúde conveniada, contribuem no processo de qualificação das ações de atenção integral à saúde, na qualificação das equipes municipais e oportunizam aos estudantes experiências de trabalho em equipe e constante articulação teórico-prática.

\section{CONSIDERAÇÕES FINAIS}

O presente estudo buscou contribuir para evidenciar a importância da interação teóricoprática nas intervenções em saúde coletiva, no cuidado aos usuários, de acordo com os princípios e diretrizes do SUS. Este é um dos propósitos da CURES, na perspectiva de contribuir para a formação de profissionais de saúde comprometidos com estes preceitos.

A formação e a implementação de práticas interdisciplinares por equipes multiprofissionais, ainda são desafios a serem vencidos. Estas mudanças envolvem habilidades e competências relacionadas à comunicação, tomada de decisão, liderança e atenção à saúde de todos os profissionais da equipe. $\mathrm{E}$ ainda, a capacidade de acolher, escutar e construir vínculos, tolerar diferenças dentro das equipes e destas com os usuários. A disponibilidade de aprender com o outro e experimentar-se em novas formas de intervenção são outros desafios para a formação e as práticas interdisciplinares.

A hipótese levantada inicialmente restou confirmada. Primeiramente no que tange a aplicação das teorias (doutrinas) sobre as vivências experimentadas, pode-se concluir que existe íntima relação entre ambas. Ao apresentar as práticas desenvolvidas de forma articuladas com as temáticas dos módulos do curso e, posteriormente, examiná-las sob a ótica das teorias é perceptível o enquadramento.

Por segundo, ao descrever as atividades que fizeram parte das práticas e destacar o que se tornou mais relevante neste período, é necessário dizer que a prática, em concomitância com a teoria, traz benefícios inigualáveis ao processo de ensino e de aprendizagem do estudante que se tornará um profissional de saúde, fazendo com que o sistema de saúde se torne mais qualificado e, a partir disso, também mais eficiente, humanizado e universal. Os determinantes sociais de saúde, por seu espaço evidente quando se trabalha com humanização do cuidado, configuram destacada matéria que também autoriza ao estudante empenhado em conhecer (e reconhecer), a oportunidade de observar nas suas práticas de saúde, quando profissional, talvez com mais facilidade o diagnóstico da doença, sua prevenção ou promoção, bem como, interferir diretamente no processo saúde-doença. 
Neste sentido, ao propiciar ao estudante a articulação entre práticas e teoria, mostrando como uma interage com a outra, a intersecção das mesmas, resta clarividente que a formação do discente terá acréscimo de qualidade, sempre, por óbvio, contando com o esforço e respaldo do próprio estudante, para compreensão dos conteúdos.

Não menos importante, o espaço serve não apenas para aprimorar o conhecimento e a forma de atuar (mais humanizada), mas também para possibilitar, ou ao menos facilitar que o estudante, futuro profissional, amplie o olhar e as práticas em saúde enfatizando a humanização do cuidado integral em saúde.

\section{ABSTRACT \\ Interdisciplinarity and its effects on dentistry education}

The aim of this paper is to report the interdisciplinary actions in the education process from the Dentistry Course at UNIVATES, Lajeado/RS, which have been realized in the Regional Universitary Clinic for Health and Education, describing some actions developed in 2015 and 2016 like the Waiting Room and actions of Matrix and Institucional Support. The methodology is qualitative by practice report and bibliographic research through principles of narrative research. Interdisciplinarity experiences seem to have influenced the formation process in dentistry in a positive way, seeking comprehensive care and integrality. This opportunity may have also strengthened the relationship among students and health care professionals and its actions.

Descriptors: Dental education. Interdisciplinary Research. Staff Development.

\section{REFERÊNCIAS}

1. Organização Mundial da Saúde. Administração da OMS. (Acesso em 03 mar. 2016). Disponível em: http://www. who.int./governance/en/index.html

2. Brasil. Lei $\mathrm{n}^{\circ}$. 8080, de 19 de setembro de 1990. Dispõe sobre as condições para a promoção, proteção e recuperação da saúde, a organização e o funcionamento dos serviços correspondentes, e dá outras providências. Diário Oficial da União, 20 set.1990; 180-55.

3. Brasil. Constituição (1988). Constituição da República Federativa do Brasil. Brasília, DF: Senado Nacional; 1988.

4. Coelho MTAD, Almeida Filho N. Conceitos de saúde em discursos contemporâneos de referência científica. Hist Ciênc SaúdeManguinhos. 2002;9(2):315-33.

5. Brasil. Ministério da Saúde. Secretaria de Políticas de Saúde. Projeto Promoção da Saúde. Distritos sanitários: concepção e organização o conceito de saúde e do processo saúde-doença. Brasília. Ministério da Saúde, 1986; p. 11-13.

6. Vianna LAC. Processo Saúde-Doença: Especialização em Saúde da Família. UNASUS/UNIFESP. Módulo Político Gestor. (Acesso em 05 fev. 2016). Disponível em: http://www.unasus.unifesp.br/biblioteca_vir tual/esf/1/modulo_politico_gestor/Unidade 6.pdf

7. Saúde e Cidadania [homepage na internet]. Secretaria Estadual da Saúde. Distritos Sanitários: Concepção e Organização (Acesso em 07 fev. 2016). Disponível em: http://portalses.saude.sc.gov.br/arquivos/sal a_de_leitura/saude_e_cidadania/ed_01/inde x.html

8. Badziak RPF, Moura VEV. Determinantes sociais da saúde: um conceito para efetivação do direito à saúde. Rev Saúde Públ Santa Cat. 2010;3(1),69-79.

9. Buss PM, Pellegrini Filho A. A saúde e seus determinantes sociais. Physis. 2007;17(1): 77-93.

10. Bueno RE, Moysés ST, Bueno PAR, Moysés SJ. Determinantes Sociais e Saúde bucal de Adultos nas capitais do Brasil. Rev Panam Salud Publica. 2014;36(1):17-23.

11. Freire P. Pedagogia do oprimido. 13a ed. Rio de Janeiro: Paz e Terra; 1983.

12. Fleury-Teixeira P, Vaz FAC, Campos FCC, Álvares J, Aguiar RAT, Oliveira VA. Autonomia como categoria central no conceito de promoção de saúde. Ciênc Saúde Coletiva. 2008; 13(Sup 2):2115-22. 
13. Franco CM, Franco SJTB. Linhas do Cuidado Integral: uma proposta de organização da Rede de Saúde (Aceso em 24 abr. 2016). Disponível em: http://www.sau de.rs.gov.br/upload/1337000728_Linha\%20 cuidado\%20integral\%20conceito\%20como \%20fazer.pdf

14. Brasil. Ministério da Saúde. Clínica Aplicada, Equipe de Referência e Projeto Terapêutico Singular. Rio de Janeiro: DF; 2008. 53 p.

15. Pinto DM, Jorge MSB, Pinto AGA, Vasconcelos MGF, Cavalcante CM, Flores AZT et al. Projeto terapêutico singular na produção do cuidado integral: uma construção coletiva. Texto \& contexto enferm. 2011;20(3):493-502.

16. Tavares CMA, Matos E, Gonçalves L. Grupo multiprofissional de atendimento ao diabético: uma perspectiva de atenção interdisciplinar à saúde. Texto \& contexto enferm. 2005;14(2):213-21.

17. Frigotto G. A interdisciplinariedade como necessidade e como problema nas ciências sociais. Rev Centro Educ Letras UNOESTE 2008; 10(1):41-62.

18. Ceccim RB, Feuerwerker LCM. O quadrilátero da Formação para uma área da Saúde: Ensino, Gestão, Atenção e Controle Social. Physis 2004;14(1):41-65.

19. Zabala A. A prática educativa. Porto Alegre : Artmed; 1998

20. Brêtas ACP, Gamba MA. Enfermagem e saúde do adulto. Barueri: Manole; 2006.

21. Verissimo DS, Valle ERM. A experiência vivida por pessoas com tumor cerebral e por seus familiares. Psicol Argum. 2006;24(45): 45-56.

22. Rodrigues AD, Dallanora CR, Rosa J, Germani RM. Sala de espera: um ambiente para efetivar a educação em saúde. Vivências. 2009;5(7):101-6.
23. Emerson EM. Sistema Único de Saúde em Belo Horizonte - Reescrevendo o Público; Ed. Xamã; São Paulo, 1998.

24. Brasil. Ministério da Saúde. Secretaria de Atenção à Saúde. Núcleo Técnico da Política Nacional de Humanização. HumanizaSUS: Documento base para gestores e trabalhadores do SUS. Rio de Janeiro, DF: O ministério; 2008.

25. Pereira Júnior N, Campos GWS. O apoio institucional no Sistema Único de Saúde (SUS): os dilemas da integração interfederativa e da cogestão. Interface (Botucatu). 2014;18(Supl. 1):895-908.

26. Campos GWS, Domitti AC. Apoio matricial e equipe de referência: uma metodologia para gestão do trabalho interdisciplinar em saúde. Cad Saúde Pública. 2007;23(2):399407.

27. Brasil. Ministério da Saúde. HumanizaSUS: equipe de referência e apoio matricial. Rio de Janeiro, DF: O ministério; 2004. p. 11-13.

28. Oliveira MM, Campos GWS. Matrix support and institutional support: analyzing their construction. Ciênc Saúde Coletiva. 2015; 20(1):229-38.

29. Abreu ES, Fernandes SMS, Gióia-Martins DF, Pechliye MM, Simony RF. Interdisciplinaridade, saúde e qualidade de vida no ambiente universitário: relato de experiência. Simbio-Logias. 2014;7(7):10718.

30. Souza PA, Lopes MHC, Azevedo OR. Guia de orientação técnica - SUAS $n^{\circ} 1$ proteção social básica de assistência social. Ministério do Desenvolvimento Social ao Combate à Fome Secretaria Nacional de Assistência Social. Brasília; 2005.

Correspondência para:

Andreas Rucks Varvaki Rados e-mail: andreas.rados@ univates.br Av. Avelino Talini, 171 - Bairro Universitário 95900-000 Lajeado/RS 